Vol. 1, No. 2, 2020, pp. 28-36

DOI: https://doi.org/10.2921/07essr55400

Contents lists available at Journal IICET

Education and Social Sciences Review

ISSN: 2720-8915 (Print) ISSN: 2720-8923 (Electronic)

Journal homepage: https://jurnal.iicet.org/index.php/essr

\title{
The integration of mobile learning among ESL teachers to enhance vocabulary learning
}

\author{
Hafizah Muhamad Kassim ${ }^{1}$, Nur-Ehsan Mohd Said ${ }^{2}$ \\ ${ }^{12}$ Universiti Kebangsaan Malaysia, Malaysia
}

\begin{tabular}{l} 
Article Info \\
\hline Article history: \\
Received Apr $11^{\text {th }}, 2020$ \\
Revised May $18^{\text {th }}, 2020$ \\
Accepted Jun $25^{\text {th }}, 2020$ \\
\hline
\end{tabular}

\section{Keyword:}

Integration of mobile learning English vocabulary

Attitudes

ESL teachers

\begin{abstract}
This study intended to describe seven ESL teachers' integration and their attitudes toward mobile learning (m-learning) as a tool to facilitate students in vocabulary lessons. Mobile learning is a new way to access learning content using handheld devices where mobile technology is integrated into routine teaching activities. The concept is grounded on a theoretical foundation where the mobile application is used as a tool to enhance learning. A qualitative research approach was employed for data collection and analysis in the study. Seven respondents of ESL teachers at secondary schools participated in a series of semi-structured interviews. The interview protocol was adapted from the Unified Theory of Acceptance and Use of Technology (UTAUT) to understand the ESL teachers' practice regarding the integration of mobile learning. Findings from the study indicated that the ESL teachers integrated mobile learning in their teaching due to its functionality in enhancing English language learners' vocabulary learning. The study indicated that the teachers considered mobile learning as necessary and a convenient type of learning while displaying positive attitudes towards the integration of mobile learning. Regardless of their length in service or volition, mobile learning is seen as one of the many useful tools that facilitate vocabulary lessons.
\end{abstract}

\section{Corresponding Author:}

Hafizah Muhamad Kassim, University Kebangsaan Malaysia, Malaysia

Email: hafizahmkassim@yahoo.com

\section{Introduction}

ESL teachers need to teach English vocabulary efficiently even it is not focused on the lessons as teachers often emphasize the development of students' linguistic competence in reading, writing, listening, and speaking more. The recent concern in Malaysia education is that a majority of English as a Second Language (ESL) students are reported having a limited vocabulary inventory, which has affected the level of their English proficiency (Chiew \& Poh, 2013; Varatharajoo, 2015). This study sees a need to enhance vocabulary teaching practices through new types of learning, such as the use of mobile learning, as a way to improve vocabulary learning. Technology-embedded tools are seeing as a new trend, and it is close to students' interest and preference. In this regard, there are still limited studies on the integration of mobile learning to vocabulary enhancement regarding teachers' views. This concern warrants further investigations on this type of learning, specifically on how teachers' usage of mobile learning in the teaching and learning process. Teachers will continue to overlook English vocabulary as an essential component to enhance students' competency in English if it is not highlighted in studies. This study hence aims to understand teachers' use and attitude in using mobile learning in teaching vocabulary lessons. As a result, educators, teachers, and administrations would give a higher priority on technology-embedded learning for the betterment of teaching languages. 


\section{Defining Mobile Learning}

It is a common perception that knowledge is indirectly transmitted from teachers to students. However, more contemporary learning theories posit that students can construct and acquire their knowledge through experiences. The interactive learning environment allows students to play an active role in the teaching and learning process so that they can obtain meaningful knowledge (Chandler, Park, Levin, \& S.Morse, 2013). In this context, learning can occur either informally as individuals (e.g., students) experience their everyday lives, as well as formally through lessons taught in schools or universities and through observations.

In today's world, learning is not confined to the classroom, and knowledge does not come solely from teachers. In recent years, there are many new technologies introduced to enhance learning. One of the latest technologies introduced in education is Mobile learning or M-learning, which combines mobile technology with traditional instruction practices. M- learning is a subset of electronic learning as it uses electronic devices, and in recent years, handheld devices and portable technology like PDAs, smartphones, IPads and tablets are widely used to replace desktop or laptop computers (Ali \& Arshad, 2017; Jung, 2015). Next, mobile learning applications (apps) are lightweight software that can be installed in small devices or accessed through a wireless network (Ali \& Arshad, 2017; Farrah \& Abu-Dawood, 2018). Thus, mobile learning can refer to the use of handheld devices and portable technology, software, or programs to support learning in multiple contexts.

The M-learning approach was first introduced in Europe in the1970s when the first mobile phone was invented. M-Learning later evolves in the mid-1990s as more sophisticated mobile devices were introduced. Meanwhile, in the 2000s, research has emphasized the use of these devices to facilitate learning outside of the classroom. At the end of the year 2000, more considerable attention was given to how mobile devices, like smartphones, provide mobility and flexibility for students to seek information and knowledge anytime, anywhere (Crompton, 2013; UNESCO, 2015). These developments show how the advancement of mobile devices and communication technology benefits the field of education.

As mentioned above, in recent years, the definitions of mobile learning have broadened in line with the advancement of technology. Jung defined mobile learning as "learning using portable devices, which allows learners to learn in diverse contexts rather than being restricted to a classroom or desk" (Jung, 2015. p.221). In this regard, Materials used in M-learning are adapted from early electronic learning programs. M-learning allows teachers to provide personalized and contextualized learning materials to cater to different learners. Furthermore, m-learning advocates that it can support both formal and informal education (Little, 2013), as well as providing an eco-friendly tool and permit flexibility (UNESCO, 2015).

The discussions below highlighted the benefits of mobile learning, specifically in teaching vocabulary to ESL students. These discussions present a case to examine the level of m-learning adoption to teach students with different proficiency and in different age groups.

\section{Teachers' approach toward utilizing M-learning to teach English as a Second Language}

M-learning has changed the landscape of teaching and learning by creating a tool that allows students to learn beyond the boundaries of time and space. It also provides teachers and students with a technology-integrated environment and facilitates learning experiences (Jong, Grundmeyer, \& Anderson, 2018; Youngkyun, Hui, \& Seongchul, 2017).

Recent evidence suggests that smartphone applications (Apps) help facilitate the learning of English vocabulary (Qun, 2015) and promote autonomous learning (Howlett \& Waemusa, 2019). Besides, as compared to other teachers, language teachers are told to have shown a higher attitude towards mobile learning integration (Youngkyun et al., 2017). For example, elementary and secondary school teachers in the USA show a positive perception of using m-learning. These findings suggest that mobile learning is also applicable for ensuring successful language learning.

Many scholars have shown their interest in examining the use of mobile phones in the classroom. For example, a study by O'Bannon and Thomas (2014) has attempted to draw subtle distinctions between ownership and age that influence teachers' acceptance of using mobile phones in the classroom. They found that teachers who have aged 32 and below and those aged 33-49 own at least one smartphone, and these lead to an increase in classroom integration. However, this was not observed among teachers aged 50 and above. In the same vein, O'Bannon Waters, Lubke, Cady, \& Rearden (2017). found that $86 \%$ of teachers and $92 \%$ of students perceive that mobile phones help them in improving classroom instruction.

In Malaysia, most studies in the field of mobile learning have only focused on its use in tertiary education (Ansarin, Farrokhi, Mahboudi, \& Jam, 2017; Ferreira, Moreira, Pereira, \& Durão, 2015). Only a 
handful of studies like Nor Fadzleen, Halina, and Abdelrahman (2014), primarily focused on secondary education. The study examined the view of trainers, teachers, and secondary school students regarding mobile learning integration. The results show that $87 \%(n=130)$ of the respondents perceive that $m$-learning will play a vital role in Malaysia's education. On the contrary, Rashidah (2019), in her mixed-method research, used document analysis and a survey questionnaire to examine steps involved in designing mobile learning based lessons before embarking on the actual conception.

\section{The advantages of M-learning in teaching vocabulary}

A common concern in a second language learning is vocabulary size or the number of words that students need to acquire. Schmitt (2008) mentioned that a vocabulary size of 2000 word families is necessary for verbal communication, 3000-5000 word families for print materials, 8000-9000 word families for reading and 5000-7000 is needed for speech. In the same vein, native speakers need to know 1000 words annually, and 2000 words at the college level, and those language students must learn twice the amount for them to communicate and understand English (Peregoy \& Boyle, 2013).

As far as the advantages are concerned, mobile learning has been proven to have a significant impact on the learning of language skills. For example, Qun (2014) study found a correlation between mobile learning and vocabulary enrichment. In the study, an application called Word Learning, which contains 852 words were used with students in the experimental group. It enables students in the experimental group to improve their vocabulary knowledge compared to those in the control group who not have access to this application. The study reported the students' vocabulary knowledge was enhanced because they can visually see all learning features as essential parts of the single vocabulary item they are trying to learn.

Mix-Method research using experimental design and survey by Ramos and Valderruten (2017) found that frequent use of mobile learning is helpful to enhance listening skills and linguistics competencies for Colombian students. The results also indicate that mobile learning allows practicing vocabulary because it can be accessed anywhere at any time. Similarly, a study by Basal et al. (2016) reports an improvement in students' knowledge of idioms when mobile-embedded learning was used.

Unlike Basal et al. (2016), a study by Chih-Cheng and Ya-Chuan (2016) extends their field of research to the combination of sound and text using mobile learning integration. The results reveal that there are no differences in vocabulary learning and vocabulary gain when different multimedia presentations were used. In the meantime, using audio input to teach new vocabulary items is useful to reduce the cognitive load on learning new words and the use of graphic cues help students to recall words' meanings. The results support Jafari and Chalak (2016), who investigated the role of WhatsApp (app) and the vocabulary learning enhancement. The results report that students who were taught using this approach outperformed those in the semi-illiterate group. Moreover, the use of the app helps provide an authentic communicative situation for students and helps teachers to be aware of students' shortcomings and strengths so that teachers can plan their teaching strategies accordingly.

To conclude, one of the issues that emerge from these findings is that more studies are needed relating to vocabulary learning using the mobile learning approach in Malaysia, especially in the secondary school context. The studies reviewed mostly correlated with a tertiary level of education. In this light, there is a need for more studies on the use of m-learning among students in different age groups, particularly among younger students, to guide teachers to select available apps or learning tools that can facilitate learning.

\section{Issues and challenges to utilizing M-learning in the classroom}

Despite its advantages, several issues and challenges limit the capability of using mobile learning. These issues and challenges are considered as the external factors that influence the adoption of M-learning, and they may vary across different users. These factors have hindered the full utilization of mobile learning. Learning a second language itself poses several challenges for the students as it is indispensable to search for optimal conditions to enhance opportunities for engagement in the target language. Furthermore, these issues and challenges may hinder the adoption of new approaches, hinder proficiency enhancement, which, in return, could become an obstacle to increase ICT usage among teachers and students.

One of the challenges is that the smartphone's screen size is small. Smartphones do not provide full screens to facilitate students when reading vocabulary words. Unlike computers, the font size of the text is small, so the students may face difficulty in reading the text. Besides, some of the smartphones have limited storage, which may prevent students and teachers from downloading, uploading, and installing materials (Rana, 2012). However, Lai and Hwang (2016) and (Elaish et al. (2017) found that the pocket size of smartphones is convenient to handle instead. 
On the other hand, ownership of a handheld device with internet connectivity is also another consideration. Some students may have or may not have smartphones or any handheld devices (Farrah \& Abu-Dawood, 2018). This study, however, specified to rural school students and boarding school students who have limited ability to having smartphones to stay connected with the knowledge online across the globe. Despite these said challenges, teachers need not be too rigid in providing a conducive, new learning environment for students (Sa'don et al., 2014; Chandrakala Varatharajoo, Adelina, \& Nabeel Abdallah, 2015)

\section{Method}

Mobile learning studies predominantly relied on quantitative methods to gather information. For example, while questionnaires allow for the collection of a large amount of data, it also has been noted that they may not shed adequate details on teacher's views because it mostly depended on numerical data. On the other hand, this study used a qualitative method. A qualitative method allowed the explicit researcher to explore the respondents' views and behaviors they showed when using mobile learning. It also offered to broaden and deepen understanding of teachers' usage and attitudes regarding the integration of mobile learning.

\section{The Participants}

In this study, the data were collected from seven samples. The researchers used the purposeful selection of respondents that employed a convenience sampling of those who were willing and available to be interviewed. There were different teaching locations (four from urban schools, three from suburban school, years of experience, and age, but they were all ESL teachers of secondary school students. Four out of seven respondents had below five years of teaching experience (P3, P4, P6, P7); meanwhile, two respondents had more than ten years of teaching experience (P1, P2, P5). According to Zoltan (2007), qualitative sampling size experience, 6- 10 sample size might work well in the qualitative field. That is, "a well-designed qualitative study usually requires a relatively small number of respondents to yield the saturation and rich data that is needed to understand even subtle meanings in the phenomenon under focus" (Zoltan, 2007, p.127).

\section{The Instrument}

The interview protocol questions were adopted and adapted to suit the semi-structured interview nature from (Venkatesh, G.Morris, Davis, \& Davis, 2003). The first section was intended to collect respondents' demography and initial perception of mobile learning integration. The second section was aimed to determine the respondents' intentions for integration and their attitudes toward mobile learning that had 11 questions. Questions 1-7 were targeted at understanding the respondents' intentions of integration, while questions 8-11 were intended at revealing the respondents' attitudes. To establish validity strategies, the researchers invited three external peers as they aided in probing the researchers' thinking around parts of the research process. The researchers also conducted pilot interviews with four samples and kept a codebook to capture the meaning of the codes while constantly comparing data during the process of coding (Creswell, 2009; Given, 2008)

\section{Data Collection}

A semi-structured interview was used as the data collection. It offered a set of guiding questions that allowed the researcher to probe into implicit information alongside respondents' provided elaborative answered on the questions asked (Zoltan, 2007). Seven respondents involving ESL teachers were involved in this study. They were selected through a convenience sampling technique because there was a limit to how many respondents a researcher can contact and visit (Creswell, 2012; Zoltan, 2007). The study was later conducted through a oneon-one interview to collect in-depth data.

\section{Data Analysis}

The interviews were audiotaped, transcribed verbatims using oTranscribe ("OTranscribe," n.d.). The respondents' names were replaced with coded names (i.e., P1 and P2) to ensure the respondents' confidentiality. A thematic analysis was used to discover patterns in the findings across a set of data in response to research questions (Braun \& Clarke, 2006). Regarding this, the researchers were able to identify the patterns of meaning in the data that were noticeable and appealing to address that were respondents' intentions for devices usage and attitudes regarding the pre-determined themes. The pre-determined themes included performance expectancy, effort expectancy, social influence, facilitating condition, and attitudes in response to the factors affected the integration, namely, experience and voluntariness of use. 


\section{Results and Discussions}

The present study has described the integration of mobile learning and attitudes among ESL teachers in enhancing ESL students' vocabulary. Out of seven respondents, five respondents had been actively integrating mobile learning, although the tools used varied.

\section{Research Question 1: What are the Malaysian ESL teachers' use in teaching vocabulary using mobile learning.}

Based on the interview data, several codes related to the pre-determined themes emerged that included performance expectancy, effort expectancy, social influence, and facilitating condition that undertaken the factors influenced the integration in response to the experience and voluntariness of use.

The first theme was performance expectancy. Interviews revealed that the respondents were favorable toward the possibility of using mobile technology in supporting vocabulary lessons. The primary reasons for mobile learning integration were the benefits that they can obtain when using smartphones when teaching. The benefits reported were smartphones application (app) was a convenient, practical, functional tool.

Four respondents made this clear in the interviews that mobile learning was a convenient tool to teach vocabulary lessons. One of the respondents commented:

P6: "I think the mobile app is really helpful for the students especially for the teacher to teach them vocabulary because we can save time, we use all the words, all the vocabulary words and then we can also provide them with the pronunciation clearly. They can apply and use the vocabulary even when they are at home, not only at the school."

When asked about the effectiveness of mobile learning brought, the respondents agreed it would enhance students' learning. Hence, it would also bring benefits to their job as they selected the right tool for teaching aid. One respondent believed that mobile learning enhanced learning experience:

P1: "Teachers will not be able to teach a whole list of vocabulary to the students. When students learn vocabulary at home on their mobile using mobile app, students will learn more vocabularies and they can use these vocabularies in their writings."

The second theme that provided answers was effort expectancy, which associated with the degree of ease of mobile learning use. It was the individual who believes that the application was easy to be used. When asked about which elements they found it helped in assisting teaching vocabulary lessons, all respondents provided answers such as mobile learning was easy to be used, it offered usability and readily content, and comprehensive. One respondent replied:

P1: "It is because... when it is online or offline, there would be a certain number of vocabularies. The designer of the app has already targeted certain number of vocabularies that the app users should know. How it makes me... easy is that there would be some vocabularies which are used in the classroom. There are some vocabularies in the app which teachers do not teach in the classroom because in the classroom there are some students who are advanced, average, and weak. So, most of the time teacher will have to use words which are understood by every student. So, when student learn it on their own, at their own pace on their mobile phone, all these three groups of students will be able to learn more vocabulary."

Most importantly, almost all apps introduced were free of use. P4 commented, "...The mobile app is free, where you can get it from the app store, google store and it's total vibrant, engaging, you can have sound, images, so it is more interesting rather than watching whiteboard."

In the aspect of complexity, it was perceived as relatively difficult to understand and use. When asked about whether mobile learning took teachers' time from the regular duties, the respondents disagreed and shook their heads. This response told an example in a real situation in which it was unusual for students to receive personal attention in the classroom due to time constraints and equipment setup took a long time. Nevertheless, the troubles would be resolved when using the mobile app because students can access the learning materials at home or anywhere, they desired.

P5: "No. No. I don't think so because of like I said, in the real classroom, not using the mobile app, that might take my time longer. That means if I were to teach vocabulary in the classroom, we have board, physical equipment of teaching and the time in class is limited compared to the mobile app, students can access according to their own time so by doing so, they can actually learn vocabulary more often and effectively."

The third theme was the social influence, which is defined as an individual perceived that significant others believed one should use the new system (mobile app) as a way to facilitate students learning. It suggested that social influences have a direct effect on intention. It is one of the reasons for the voluntariness of 
use to conform to social expectations or initiated the integration. The individual intends to comply with social influence. When asked who influenced their intention on using mobile learning, all respondents responded to stakeholders that included government officials, school board members, administrations, and parents.

P1: "Who are those people? The Kementerian. They advised to use since we are in the twenty-first century learning setting. So, one of them is to use technology. So, mobile application is under the use of technology."

P1: "Beside Kementerian, the SISC+, teachers, coach and admin."

After all, the respondents were the ones who decided whether to integrate mobile learning in teaching or not. Hence, the latter question asked their intention of integrating mobile learning, whether it was based on their initiative or partly because others influenced them.

P4: "It is my initiatives. Because I can see that English is different other than any subjects and it should be fun, engaging. So to make the lesson entertaining, I need to use what is closer to the students which is the mobile. So, we use mobile learning."

The next theme was related to facilitating conditions which were showed when individual believed that there was an organizational and technical infrastructure to support the use of mobile learning. The construct discussed in this study was compatibility in which it referred to which an innovation is perceived as being consistent with existing values, needs, and experiences of potential adopters (Venkatesh, Thong, \& Xin, 2012).

The teachers who were interviewed considered mobile application usage as a fun, interactive, adaptability tool. A respondent found a mobile app as an interactive, which she used to engage with the students. Hence, mobile learning worked well with this respondent. It was because, aside from mobile learning was something new; its functionality and user interfaces were also fun and interactive.

P6: "For me, I think it fits well because sometimes the students don't like the teaching aids on a whiteboard or from the book. They want to watch something or listen to new things. I think by using this one thru a computer and display for them. they want something different. Yea, I think is the best way. We can just guide them and they can use it."

P3: "Because there are a lot of features of mobile apps. There are a lot of activities and I can choose which one is good for my students according to their level. For example, there are beginners so I will choose simple vocabulary activity to teach to them."

Based on the findings, it is believed that the characteristics of the mobile application attract the English teachers in integrating mobile learning into teaching. The findings of this study are in line with the findings of (Sarrab, Elbasir, \& Alnaeli, 2016), whom found that mobile learning could lead to positive effects in learning environments because of its functions like availably, quick response, flexibility, scalability, usability, maintainability, functionality, reliability connectivity, performance, user interface and security.

\section{Research Question 2: What is the Malaysian ESL teachers' attitude towards teaching vocabulary using mobile learning?}

Teachers' attitudes were indirect determinants of integration of mobile technology in education among educators (Venkatesh et al., 2003, 2012). This study is associated with the teacher's overall liking to use mobile learning. Although it was considered an indirect determinant, it still had a degree of influence on total teachers' satisfaction in using technology. When they satisfy utilizing the type of teaching, they likely to show positive attitudes to integrate technology in the lessons actively.

Data analysis revealed that almost all respondents showed positive feelings about using mobile learning as one of the teaching tools, except a respondent showed a moderate negative attitude. A respondent encouraged teachers to equip themselves with the latest technology as it was becoming one of the essential tools in $21^{\text {st }}$ learning:

P2: "If we are using it the right way, it will be a very good tool for us to teach for example teaching vocabulary or maybe teaching and learning process because mobile apps is really close to the student nowadays. So, we cannot deny the fact that we are currently teaching in the 21 st century so we must equip ourselves with the latest technology and somehow rather we have to follow the technology."

On the contrary, the respondent who showed a moderate negative feeling, however, tried to be realistic as mobile technology can also be both advantageous and disadvantageous for teachers. The excerpt was taken from the respondent:

P4: "It can be both. It can be good because while they are using their mobile phones, they can always learn new vocabulary. But it can also be bad where the teacher is having the difficulties to assess their performances and we don't know either the students are learning through the mobile app or not." 
The respondent agreed that students can always learn English vocabulary. However, she also expressed her worries about not knowing whether the students are learning or got distracted when using smartphones as well as assessing students' performances. Teachers cannot evaluate the students' performance after one topic covered because they cannot see the students' works or exercise as they always do with the exercise books or tests.

Next, they found that using mobile learning was also fun and enjoyable because of many reasons. Mobile learning was enjoyable because of its interactivity, portability, and convenience. Moreover, it can even kindle students' personal interest. These reasons had encouraged the teachers intrinsically. For instance,

P4: "It is enjoyable when the students show their interest and when the students show their progress. I mean, when they answered the quizzes and we can see their improvement. That is my kind of enjoyment."

P6: "Sometimes when we use technology so the students will be excited to watch the pictures, they can click here and there. The students nowadays they prefer to be by their own rather than we provide and prepare for them. So, I think it will be enjoyable for the learning process."

P7: "It has some graphics so that the students can imagine it well with certain graphics and can pronounce it well because there is audio."

When asked, what makes them think a mobile app makes work more interesting? They thought their works became more interesting when the mobile app was fun and convenient to be used. It can be exciting when it can stimulate teacher's and students' interest.

P3: "I think my school... mobile app is something new. So, by using mobile app, it will make learning to be different. So, teachers and students need to discover new thing every day. So, I think it is interesting."

P6: "Because of all the details and the notes that we need are provided there. I just have to click and have to make sure about the internet connection, and the rest we can just let them do by themselves."

When asked whether they looked forward to works that require them to using mobile learning, most of them were anticipated to employ mobile learning in the teaching process. The following extracts were the responses from the respondents:

P1: "It assists teachers in their teaching process. It makes the lesson interesting. two-third of the classroom may own their handphones. It reduces the delivery process of teaching vocabulary in class."

P2: "So when teaching grammar or the four skills it really helps you to perform better in class in teaching and also it works as a teaching aid for you. And it will not make the lesson boring because the students are working with their phones, something that they like, something that is up to date compared to the traditional way of writing in a book or compared to. It is like a game .. a game time for students."

P4: "For the aspect, like I said it is easy and saves time. That is for the teacher. For my aspect of job but for students from those mobile apps they can get benefits for their reading and listen especially listening when they can listen to the correct pronunciation. That is important especially for PT3 students they have speaking and listening tests. about grammar and writing, It can help either but it is nothing much as reading and listening."

The responses were varied because they had different reasons and goals in using mobile learning for teaching. P1 looked forward to using mobile learning as it will make the delivery process of teaching vocabulary lesser as the students can learn using mobile devices after class hour while P2 will continue to use mobile learning because it will make the teaching enjoyable. Also, P4 interesting in using mobile learning because of its benefits for both teachers and students.

Teachers' good feelings in integrating mobile learning are linked to the students' beneficial gains. The findings are corresponding with the findings of (Ligi \& Raja, 2017), which indicated that mobile leaning piques both teachers' and students' behavioral intentions because of its influencing factors. Mobile learning offers useful features of devices, user's expectations, and pedagogical advantages. For example, in terms of pedagogy gains, mobile learning offers flexible learning, blended learning, and interactive learning. Similarly, the findings of (Hashim, Yunus, \& Embi, 2018) found that mobile learning could bring more affordances than constraints. Mobile learning can increase interest in ESL learning. Furthermore, mobile learning is accessible because it is fast, flexible, and easy as well as it can facilitate ESL learning. 


\section{Conclusions}

Based on the findings of this study, it can be summarized that mobile learning is a useful education tool in facilitating ESL teachers to teach vocabulary effectively, regardless of time and place. The feature makes it possible to be implemented in remote areas and for emergencies that require distance learning. Some of the factors involved in successful integration include its function as an interactive, convenient, and universal tool. Mobile learning is convenient for both teachers and students, and due to that, the teachers show positive feelings in integrating this technology-embedded in the lessons regardless of length in service or volition. When teachers are interested in integrating mobile learning, their level of confidence and acceptance in technology increases. This result, in return, benefits students in terms of technology awareness and vocabulary enhancement. Therefore, it would best if teachers start using online learning in teaching English vocabulary. Thus, this study is hoped to increase awareness among educators, decision-makers, and shareholders in understanding teachers' intentions that determine a successful integration. For future research, it is suggested that the researchers using mix-method research that requires to use more than one method of data collection or research that investigate teachers and students' perception of using mobile learning. This methodology offers the opportunity to influence a broader audience among academicians, policymakers, as well as app and website developers. Finally, researchers can also consider viewing the perspective of the Diffusion of Innovation (DOI) model in investigating the dominance of the characteristics in adopting mobile learning among English teachers.

\section{References}

Ali, R. A., \& Arshad, M. R. M. (2017). Investigating the perception of students regarding M-learning concept in Egyptian schools. International Journal of Interactive Mobile Technologies, 11(6), 112-122.

Ansarin, A. A., Farrokhi, F., Mahboudi, H. R., \& Jam, Z. A. (2017). Attitudes towards smart phones and tablets. International Journal of Applied Linguistics and English Literature, 6(5), 66.

Basal, A., Yilmaz, S., Tanriverdi, A., \& Sari, L. (2016). Effectiveness of mobile applications in vocabulary teaching. Contemporary Educational Technology, 7(1), 47-59.

Braun, V., \& Clarke, V. (2006). Using thematic analysis in psychology. Qualitative Research in Psychology, 3(2), 77-101. https://doi.org/10.1191/1478088706qp063oa

Chandler, T., Park, Y. S., Levin, K. L., \& S.Morse, S. (2013). The incorporation of hands-on tasks in an online course: an analysis of a blended learning environment. Interactive Learning Environments, 21(5), 456-468.

Chiew, P. N., \& Poh, K. N. (2013). Teaching strategies and their impacts on the English proficiency of young Malaysian learners. In Frontiers of Language and Teaching (pp. 186-195).

Chih-Cheng, L., \& Ya-Chuan, Y. (2016). Effects of presentation modes on mobile-assisted vocabulary learning and cognitive load. Interactive Learning Environments, 1-15.

Creswell, J. W. (2009). Research design: Qualitative, quantitative, and mixed methods approaches (3rd ed., Vol. 8). Cambridge: Sage Publications, Inc.

Creswell, J. W. (2012). Educational Research (4th ed.). Boylston: Pearson Education.

Crompton, H. (2013). A historical overview of M-Learning:Handbook of mobile learning. In Z. L. Berge \& M. Lin Y. (Eds.), Handbook of Mobile Learning. Routledge.

Elaish, M. M., Shuib, L., Abdul Ghani, N., Yadegaridehkordi, E., \& Alaa, M. (2017). Mobile learning for English language acquisition: Taxonomy, challenges, and recommendations. IEEE Access, 5(September), 19033-19047.

Farrah, M. A. A., \& Abu-Dawood, A. K. (2018). Using mobile phone applications in teaching and learning process. International Journal of Research in English Education, 3(2), 48-68.

Ferreira, M. ., Moreira, F., Pereira, C., \& Durão, N. (2015). The role of mobile technologies in the teaching/learning process improvement in Portugal: A literature review. ICERI Conference, (November 2015), 4600-4610.

Hashim, H., Yunus, M. M., \& Embi, M. A. (2018). Learning through mobile: Exploring the views of Polytechnic ESL learners. Journal of Teaching \& Learning in Multicultural Contexts, 2(1), 56-62.

Howlett, G., \& Waemusa, Z. (2019). 21st century learning skills and autonomy: Students' perceptions of mobile devices in the thai EFL context. Teaching English with Technology, 19(1), 72-85.

Jafari, S., \& Chalak, A. (2016). The role of WhatsApp in teaching vocabulary to Iranian EFL learners at junior high school, $9(8), 85-92$.

Jong, D. De, Grundmeyer, T., \& Anderson, C. (2018). Comparative Ssudy of elementary and secondary teacher perceptions of mobile technology in classrooms. International Journal of Mobile and Blended Learning, 10(1), 12-33. 
Jung, H. (2015). Fostering an English teaching environment: Factors influencing English as a foreign language teachers ' adoption of mobile learning, 219-241.

Lai, C. L., \& Hwang, G. J. (2015). A comparison on mobile learning preferences of high school teachers with different academic backgrounds. In 2015 IIAI 4th International Congress on Advanced Applied Informatics (pp. 259-263).

Ligi, \& Raja, W. D. (2017). Mobile learning in higher education. Index Copernicus Value, 5(4), 1-6.

Little, B. (2013). Issues in mobile learning technology. Human Resource Management International Digest, 21(3), 26-29.

M.Given, L. (Ed.). (2008). The SAGE Encyclopedia of Qualitative Research Methods. A Sage Reference Publication. California: Sage Publications.

O'Bannon, B. W., Waters, S., Lubke, J., Cady, J., \& Rearden, K. (2017). Teachers and Students Poised to Use Mobile Phones in the Classroom. Computers in the Schools, 34(3), 125-141.

O'Bannon, Blanche W., \& Thomas, K. (2014). Teacher perceptions of using mobile phones in the classroom: Age matters! Computers and Education, 74, 15-25.

OTranscribe. (n.d.). Retrieved from https://otranscribe.com/

Peregoy, S. F., \& Boyle, O. F. (2013). Reading, Writing and Learning in ESL: A Resource Book for Teaching K-12 English Learners (6th ed.). Boston, MA: Pearson.

Qun, W. (2014). Learning ESL vocabulary with smartphones. Procedia - Social and Behavioral Sciences, 143(2014), 302-307.

Qun, W. (2015). Pulling mobile assisted language learning (MALL) into the mainstream: MALL in broad practice. Plos One, 10(5), 1-12.

Ramos, L., \& Valderruten, A. (2017). Development of listening and linguistic skills through the use of a mobile application. English Language Teaching, 10(9), 95-107.

Rana, S. S. (2012). A study of use of mobile phones for teaching \& learning purpose. International Journal of Science and Research, 3(6), 2765-2567.

Rashidah, R. (2019). Designing mobile learning: Empirical journey to reality in Malaysian secondary school context. EduLite: Journal of English Education, Literature and Culture, 4(1), 13-24.

Sa'don, N. F., Dahlan, H. M., \& Ibrahim, A. (2014). Usage of mobile learning in Malaysian secondary education: Stakeholders' view. Journal of Information Systems Research and Innovation, 6, 42-50.

Sarrab, M., Elbasir, M., \& Alnaeli, S. (2016). Towards a quality model of technical aspects for mobile learning services: An empirical investigation. Computers in Human Behavior, 55, 100-112. https://doi.org/10.1016/j.chb.2015.09.003

Schmitt, N. (2008). Review article: Instructed second language vocabulary learning learning. Language Teaching Research, 12(3), 329-363.

UNESCO. (2015). Evolution and prospects for the use of mobile technologies to improve education access and learning outcomes.

Varatharajoo, C. (2015). Morphemic analysis awareness: A boon or bane on ESL students' vocabulary learning strategy. World Academy of Science, ..., 9(9), 3263-3269. Retrieved from http://www.waset.org/publications/10002391

Varatharajoo, Chandrakala, Adelina, A., \& Nabeel Abdallah, M. A. (2015). The awareness of morphemic knowledge for young adults' vocabulary learning. The Malaysian Online Journal of Educational Sciences, $3(2), 45-56$.

Venkatesh, V., G.Morris, M., Davis, G. B., \& Davis, F. D. (2003). User acceptance of information technology: Toward a unified view. Mis Quarterly, 27(3), 425-478.

Venkatesh, V., Thong, J. Y. ., \& Xin, X. (2012). Consumer acceptance and use of information technology: Extending the unified theory of acceptance and use of technology. MIS Quarterly, 36(1), 157-178.

Youngkyun, B., Hui, Z., \& Seongchul, Y. (2017). Teachers ' attitudes toward mobile learning in Korea. The Turkish Online Journal of Educational Technology, 16(1), 154-163.

Zoltan, D. (2007). Research methods in applied linguistic. Great Clarendon Street: Oxford University Press. 